\title{
Musculocontractural Ehlers-Danlos syndrome
}

INSERM

\section{Source}

INSERM. (1999). Orphanet: an online rare disease and orphan drug data base.

Musculocontractural Ehlers-Danlos syndrome. ORPHA:2953

Ehlers-Danlos syndrome, musculocontractural type is a congenital form of Ehlers-Danlos syndrome characterized by distinct craniofacial features, multiple contractures, progressive joint and skin laxity, adduction-flexion contractures of the thumbs, talipes equinovarus, bruisability and multisystem frag ility-related manifestations. 